\title{
Imperial Botanical Conference
}

$\mathrm{T}$ HE Imperial Botanical Conference which met on August 27-30 in the rooms of the Linnean Society, Burlington House, London, is the third of a series which dates from the years immediately following the War. At that time, the International Botanical Congresses, initiated in pre-War years, which were due to be held at five-yearly intervals, were in abeyance. Thanks to the efforts of a committee of British botanists a conference of Empire botanists, on a scale fairly comparable to that of an International Congress, was arranged for the year 1924, and took place in London. Quite apart from its value to scientific botany generally and to the advancement of botanical study within the Empire in particular, that Conference undoubtedly acted as a stimulus to the resumption of normal friendly relations between European botanists which had been sadly interrupted.

Now that the International Congresses are again established-first at Ithaca, N.Y., in 1926, then at Cambridge in 1930, and in the present year at Amsterdam-the need for Imperial Conferences has to some extent disappeared, at least from the point of view of general botanical science. It was felt, however, that such conferences would still serve a useful purpose in relation to problems of special Imperial interest, to the organisation of research, and not least to the formation of contacts between widely scattered groups of workers. A small committee was therefore kept in being. A short conference, of a purely formal nature, was held in 1930 , and now the third of the series has taken place. The subjects for discussion were limited to those of general economic interest to the Empire, and were in the main suggested by botanists overseas.

In his address of welcome to members, the president, Sir Arthur Hill, emphasised the everincreasing importance of botanical research in the development of Imperial agricultural resources, not merely with regard to crops which figure in export trade, but also to the food plants of the native and his animals. The study of native crops with the view of obtaining maximum yields under the various local conditions is a work of the greatest national importance which calls for the continued co-operation of botanical and agricultural workers at home and overseas.

\section{PASTURE RESEARCH}

Prof. R. G. Stapledon, in introducing a series of papers on "Pasture Research Within the Empire", dealt with the importance of 'strain' in pasture plants. Studies at Aberystwyth have abundantly shown that grassland plants are no exception to the general rule that botanical species contain within their ambit a more or less indefinite number of strains or varieties. Between the strains of a particular grass or clover there might be a greater difference in agricultural value, for example, permanence in the pasture, feeding value, economic return, etc.- than there is between desirable and undesirable species. These strains or groups of strains have been evolved on a geographical basis, partly in response to climatic and soil conditions, but probably to a large extent as a result of long-continued farming practices. The work of the plant breeder is in the first place to discover which are the most desirable of these local groups for special purposes, and then to ensure that in commercial exploitation any tendency to deterioration is effectively checked. The sowing out of pure strains is not desirable inasmuch as a certain degree of variability gives some insurance against the vagaries of climate and of farming practice. The maintenance of pure strains, with subsequent judicious blending, is a splendid ideal which is very difficult to achieve and is in fact not necessary. The difficulty of maintaining the quality of a certain group of strains ('ecogroup') is not so great as is sometimes imagined and can be overcome for all practical purposes if the work is carried out in a suitable locality and on a large enough scale. The essential point is to safeguard the quality of the original stock, and this can only be done under the direct control of the plant breeding station.

The problems involved in the improvement of pastures in the Dominions were outlined by Dr. I. B. Pole-Evans for the Union of South Africa, and by Prof. G. W. Scarth and Mr. H. J. Whyte for eastern Canada. Dr. Pole-Evans described the natural pasture areas of the Union, and in this connexion exhibited a comprehensive series of coloured plates illustrative of the South African flora. Much damage to natural pastures has already been done by indiscriminate grazing, by burning and by other malpractices. This he ascribed to a general absence of fundamental knowledge relating to the problems of veld management. He reviewed the research work which has been carried out in the Union up to the present and stated that a national research programme has now been organised which will deal in particular with problems relating to the general decline in the carrying capacity of the veld due to faulty grazing methods. This programme will also aim at the building up of an organised animal industry based on the development of the natural pasture potentialities of the country.

In presenting the Canadian problems, Prof. Scarth pointed out that the natural pastures of eastern Canada are at the moment the most important in the Dominion, inasmuch as they carry more than half of the total livestock. A striking feature is that though these pastures have never been ploughed, the significant part of the herbage consists of introduced European plants which have in course of time colonised these areas. The pastures are generally poor and the trend is towards further deterioration. A very comprehensive programme of research, organised both on a Federal and on a State basis, is now being carried out, involving ecological mapping in association with soil surveys, manurial trials in relation to quantity of herbage and to stock rearing or milk production, biochemical studies of pasture plants, etc. The main result so far established is that the pastures as a rule respond markedly to the addition of phosphatic fertilisers, the poor type of Agrostis sward being replaced in time by the better grasses with clovers. The formulation of recommendations applicable to the different soils and climates will only be possible after vigorous research over many years. An ecological study of certain 
pastures of eastern Canada was presented by Mr. H. J. Whyte and served to illustrate the poor quality of many of these and the need for improvement.

Certain detailed aspects of pasture research in England were described by Mr. G. E. Blackman and by Mr. Martin Jones of the Jealotts Hill Research Station of Imperial Chemical Industries, Ltd. Mr. Blackman showed that under spring conditions, nitrogenous manuring stimulates growth within a certain temperature range only. During midseason, water supply rather than nitrogen is the controlling factor. The effect of light on the growth of pasture plants is complex, varying with the species, with the available nitrogen supply and even with the form in which the latter is added.

Mr. Martin Jones dealt with the competition to which the constituents of grassland are subjected by neighbouring plants and showed how differences in habit or rate of growth lead to the dominance of certain forms or the suppression of others. Grazing by animals is of the greatest importance in this connexion, the effects on the development of any particular constituent varying according to the intensity of grazing at any given period. The correct management of grazing is therefore essential for the maintenance of any particular type of pasture.

\section{TROPICAL FORESTS}

In a session devoted to "Succession of Tropical Forest Types" Dr. Burtt Davy dealt with the evolution of tropical African forest types and pointed to the presence of a considerable percentage of IndoMalayan forms in West Africa though they are no longer to be found in East Africa. He attributed this peculiar distribution to elevation of the land surface, subsequent to migration, with resulting lowering of temperature and desiccation of considerable areas of low country. It was therefore suggested that lowlevel, broad-leaf tropical rain-forest was at one time more widespread in East Africa than it is now. The presence of a small but significant palæoarctic element extending from Abyssinia as far south as temperate South Africa indicates relatively modern immigra. tion along the temperate zone corridor formed by the high eastern mountain chain.

The distribution of forest types in Nyasaland was briefly described by Mr. P. Topham. The range of elevation within the region extends from $200 \mathrm{ft}$. to $10,000 \mathrm{ft}$. and at least nine groups of forest types are to be noted. The biotic factors of greatest importance in relation to distribution are local history, bush fires, cultural methods, fallow periods, grazing and soil rejuvenation by termites. In the absence of longterm fire protection experiments and of fuller local records, the ecological succession of the different types is largely speculative.

The distribution of various Nigerian forest types in relation to temperature, rainfall and elevation was described by Mr. W. D. MacGregor, and particular stress was laid on the succession from the open parkland to the moist deciduous type of forest. Experiments have shown that over considerable areas such a succession takes place with fair rapidity provided there is a nucleus of deciduous forest sufficiently near to supply an abundance of wind-borne seed and provided the area is protected from farming and, in its earlier phases, from grass fires. The importance of enlarging the area of deciduous forest as a check to advancing desiccation from the Sahara was emphasised.
Mr. P. Richards gave a comparative account of three areas of tropical rain forest situated in British Guiana, Sarawak and Nigeria respectively. Each area was studied intensively rather than extensively, and the data were collected so far as possible in a quantitative form. The structure was studied by means of profile diagrams based on measurements of all the trees on clear-felled plots, and the floristic composition was at the same time determined. The structure is fairly similar in all three localities. An interesting point is the close analogy of the forests on white sand in Sarawak and British Guiana, suggesting that there may be parallel edaphic variations from the climax in different regions of the tropies.

An ecological investigation of peculiar interest was described by Mr. C. G. Trapnell in relation to the application of ecological methods to the study of native agriculture in Northern Rhodesia. Various native tribes have discovered-some more exactly than others - the association of certain wild plants with soils of a certain type and are able to fix on the location and decide on the nature of their cultivated crops in accordance with such observations. Efforts to advance the prosperity of the country should be directed towards building on the foundations already laid by the native himself, rather than to hazardous introductions or innovations.

\section{FRUIT STORAGE}

The enormous amount of research, much of it emanating from Empire sources, which has in recent years been directed to problems of fruit storage and transport, made it peculiarly suitable that a session of the Conference should be devoted to that subject. The fact that, as one speaker pointed out, imports of Empire fruit into the British market have increased six-fold in the last twenty-five years and now constitute nearly half of the total import shows how research and the practical application of it are proceeding hand in hand with the advancement of Imperial trade.

Of the eight papers presented, five came from overseas contributors and the remainder from workers of the Food Investigation Board. The problems involved are of extraordinary complexity, involving as they do not merely the factors which immediately affect storage of fruit-for example, temperature and humidity of the store, mode of packing, state of maturity of fruit when put in the store, etc.-but a multitude of others which come into play while the fruit is still on the tree. Such are the effects of soil, of climate, of rootstock and so forth on the keeping quality of the fruit. The problems are in the main similar whatever the fruit or the country of origin, though the relative importance of the different factors may vary from one problem to another. For these reasons no summary which would even indicate details will be attempted here.

Dr. C. Wardlaw and Mr. R. Leonard discussed the problems of the storage of tropical fruit. Investigations at the Imperial College of Tropical Agriculture range from empirical testing of the storage behaviour of various tropical fruits-banana, lime, grape fruit, avocado pear, etc.-to fundamental studies of the gaseous exchange occurring during growth and ripening. Canadian researches, summarised by Dr. H. T. Güssow, covered the whole field of the storage of apples. Mr. H. Turner of the New Zealand Fruit Board dealt chiefly with systems of refrigeration and 
methods of stacking fruit in the holds of ships. Mr. N. F. Holmes, in connexion with the transport of Australian citrus fruit, discussed fungal spoilage and loss of flavour in relation to age of the fruit, and the value of various methods as tests of the state of maturity, while Mr. D. J. Dreyer described experiments relating to mechanical damage to South African pears. With reference to the gas storage method, which has been rapidly taken up by some English growers of apples in the last few years, Dr. C. West advised a certain amount of caution, as much research work still remains to be done before the method is placed on a sound basis. Finally, papers of a fundamental nature were read by Dr. A. S. Horne and by Mr. R. Gane, the former discussing the results of a quantitative study of the resistance of apples to fungal invasion and the latter dealing with some interesting effects of ethylene gas on the respiration and maturing of banana fruit.
In the final session, Prof. E. E. Cheesman directed attention to the pressing need for greater facilities within the Empire for the collection and classification of crop varieties and related species. The menace of Panama disease and of witch-broom disease to banana and cacao cultivation respectively makes it imperative that wholehearted attempts should be made to discover or to breed suitable varieties of the crop plants resistant to these diseases. The work is seriously handicapped at the moment by the lack of adequate facilities.

An interesting feature of the Conference was a series of exhibits comprising, in addition to the illustrations of South African plants already mentioned, a collection of types of cultivated Sorghum and of cowpea (Vigna sp.) prepared by the staff of the Royal Botanic Gardens, Kew, and an exhibit illustrating Linnæus's development as a botanist arranged by the Librarian of the Linnean Society.

\section{Conference of Empire Meteorologists}

$\mathrm{T}$ WENTY-FIVE Dominions and Colonies were represented at the third Conference of Empire Meteorologists which was in session at the Meteorological Office, South Kensington, on August 12-21. Six years have elapsed since the previous conference and there have been important changes during that period, both in the organisation of colonial meteorological services and in the demands made upon them for data, either for home consumption or for international dissemination. There were two main reasons for calling the conference, first to give the directors of services an opportunity of discussing their problems before proceeding to the International Conference of Directors to be held at Warsaw this month; secondly, to discuss the meteorological arrangements necessary to meet the Government's requirements in connexion with the Empire air-mail scheme.

At the same time, the meetings provided an opportunity for the exchange of views on many other questions of a general character. In meteorology, problems of co-ordination are not less important than purely technical problems. It is, therefore, very necessary that the administrators of meteorological services should meet from time to time to discuss these matters. Within the Empire we have a wide diversity, not only in climate but also in the administrative arrangements for handling meteorological data. A meeting of Empire meteorologists thus provides a means for considering problems from every angle, and has a special value for that reason.

At the opening meeting on August 12, the delegates were welcomed by Sir Henry Lyons, vice-chairman of the Meteorological Committee. Mr. J. Patterson, director of the Canadian Meteorological Service, was elected president of the Conference. At the first business meeting, the Government's policy in regard to the Empire air-mail scheme was outlined. This scheme involves both day and night flying, and adequate meteorological services must be a fundamental part of the necessary ground organisation. Linked up with the question of organisation are such technical matters as the making of synoptic charts on a uniform plan, the coding of reports from land. stations and ships and the choice of hours of observation. Air-mail pilots are familiar nowadays with synoptic charts, and it is important that they should be able to consult up-to-date charts at their ports of call. It is also important that a symbol they see on a chart in one country should have the same meaning as a similar symbol on a chart they see in another country. The delegates will have to consider the international aspect of this matter of symbols at Warsaw, and the discussion in London proved very useful.

Questions connected with aviation and with synoptic meteorology occupied the first few meetings. These were followed by discussions on meteorology for the Army and for the Navy, instruments, upperair observations, marine meteorology, geophysics, climatology and agriculture, and seasonal forecasting. The use of upper-air data has assumed increased importance with the advent of air-mass analysis for the purpose of synoptic diagnosis. In many colonies there are special difficulties, however, in the way of obtaining the data. One difficulty is that of procuring hydrogen for the inflation of pilot balloons, and it was of interest to learn how the difficulty is being met in Canada by the use of a portable electrolytic generator, and in East Africa by an ingenious chemical generator, the essential part of which has been adapted from a commercial pressure-cooker.

In connexion with geophysies, the Conference passed a resolution recommending the establishment of a station at Chesterfield Inlet, Hudson's Bay, Canada. This station would be in near proximity to the North Magnetic Pole and its situation would also be very favourable for auroral studies. The conference also recommended the establishment of a station at Tristan da Cunha, observations from which, situated as it is about midway between the Cape of Good Hope and South America, would be of great value.

The discussions on climatology and agriculture began on August 19. Perhaps the most interesting subject in these categories was that of the broadcasting of climatological data. Students of world climatology have previously been handicapped 